\title{
Navigator gated flow sensitive gradient echo sequence for quantification of aortic valve regurgitation
}

\author{
Jonathan Nadjiri ${ }^{1 *}$, Caroline Sonne ${ }^{2}$, Eva Hendrich ${ }^{1}$, Albrecht Will ${ }^{1}$, Cornelia Pankalla ${ }^{1}$, Stefan Martinoff ${ }^{1}$, \\ Martin Hadamitzky ${ }^{1}$
}

From 17th Annual SCMR Scientific Sessions

New Orleans, LA, USA. 16-19 January 2014

\section{Background}

Exact quantification of aortic valve regurgitation is a challenge. Patients are typically asymptomatic and echocardiography is unreliable in certain conditions, particularly in eccentric regurgitation jets. Cardiac magnetic resonance (CMR) is a valuable alternative in this situation, but the use of conventional sequences without respiration correction is limited by motion artifacts and long acquisition times caused by necessary signal averaging. Novel navigator gated flow sensitive gradient echo sequence avoid motion artifacts caused by respiration and in addition allow for a higher temporal resolution eventually leading to more reliable results.

\section{Methods}

On 31 patients with varying degrees of aortic regurgitation we performed both standard (StdSeq) and navigator gated (NavSeq) flow sensitive gradient echo sequences. Primary parameter was the regurgitation fraction defined as the quotient of anterograde and retrograde flow over a cross section of the ascendent aorta just above the maximal excursion of the aortic leaflets. Since a gold standard for quantification of aortic regurgitation is missing, we correlated these values with the enddiastolic volume of the left ventricle (LVEDV) assessed by a contiguous stack short axis cine-SSFP sequences. This parameter is directly influenced by the regurgitant volume. For comparison we
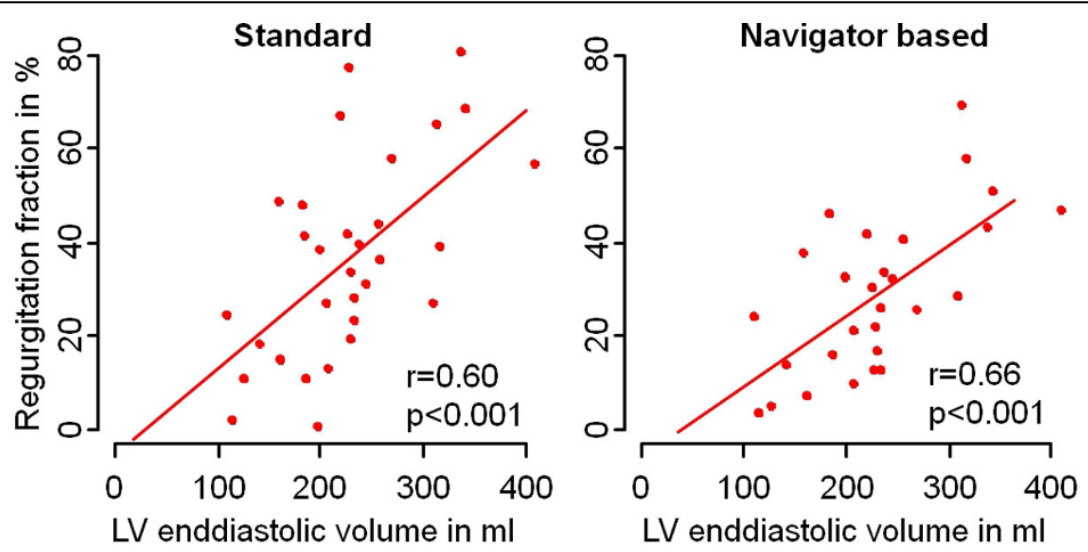

Figure 1

'Department of Radiology and Nuclear Medicine, Deutsches Herzzentrum

München, Munich, Bavaria, Germany

Full list of author information is available at the end of the article

(c) 2014 Nadjiri et al.; licensee BioMed Central Ltd. This is an Open Access article distributed under the terms of the Creative Commons 
recorded the aortic regurgitation in echocardiography using 5 degrees (mild - mild to moderate - moderate - moderate to severe -severe ) assessed by an expert echocardiographer blinded to the CMR results.

\section{Results}

Regurgitation fraction ranged from $0 \%$ to $80 \%$ and from $3 \%$ to $70 \%$ in StdSeq and NavSeq, respectively. Values of LVEDV ranged between 109 and $409 \mathrm{ml}$. NavSeq correlated best with LVEDV with a slope of 0.15 percentage points per $\mathrm{ml}$ increase and a correlation coefficient $\mathrm{r}$ of $0.66(p<0.001)$. For StdSeq the values of $r$ and slope were $0.60(\mathrm{p}<0.001)$ and 0.18 , respectively (Figure 1 below). Correlation with echocardiographic assessment of aortic regurgitation was weak with a p value of 0.03 and 0.01 for NavSeq and StdSeq, respectively, as was the correlation between the echo quantification and LVEDV $(\mathrm{p}=0.012)$.

\section{Conclusions}

Navigator gated flow quantification had a better correlation with LVEDV than the conventional non-gated sequence. The correlation to LVEDV of both CMR sequences is better than that of echocardiography. Novel navigator gated flow sensitive gradient echo sequence further improves accuracy of quantification of aortic regurgitation, this may be a valuable alternative modality for patients with inconclusive echocardiographic findings.

\section{Funding}

None.

\section{Authors' details}

'Department of Radiology and Nuclear Medicine, Deutsches Herzzentrum München, Munich, Bavaria, Germany. ${ }^{2}$ Department of Cardiology, Deutsches

Herzzentrum München, Munich, Germany.

Published: 16 January 2014
Submit your next manuscript to BioMed Central and take full advantage of:

- Convenient online submission

- Thorough peer review

- No space constraints or color figure charges

- Immediate publication on acceptance

- Inclusion in PubMed, CAS, Scopus and Google Scholar

- Research which is freely available for redistribution

Submit your manuscript at www.biomedcentral.com/submit 